\title{
AERodynamic AND Flexible TruCKS FOR NeXt Generation OF LONG Distance RoAd TransPORT \\ (AEROFLEX)
}

\section{FUNDED BY THE EUROPEAN UNION'S HORIZON 2020}

RESEARCH \& INNOVATION PROgRAM UNDER THE GRANT AgREement 769658

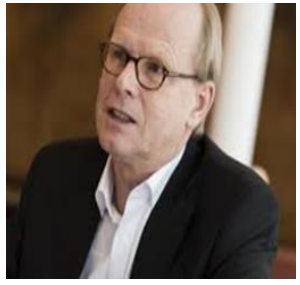

Ben Kraaijenhagen, MAN Truck \& Bus AG BEN.KRAAIJENHAGEN@ MAN.EU

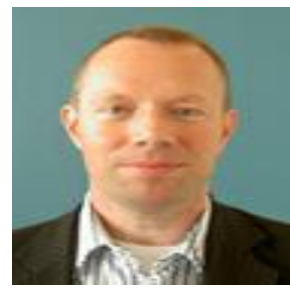

Magnus Ölback, Volvo Group BMAGNUS.OLBACK@ VOLVO.COM

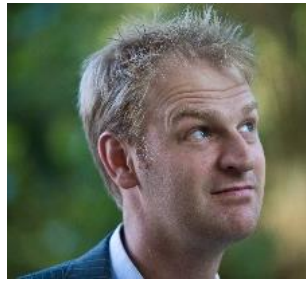

Cor van der Zweep, Uniresearch

C.VANDERZWEEP $@$ UNIRESEARCH.NL

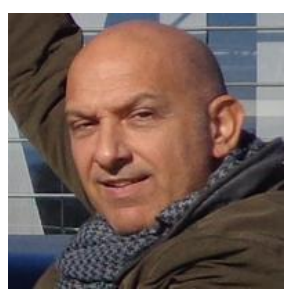

Alessio Sarcoli IVECO, CNH Group C.ALESSIO.SARCOLI@ CNHIND.COM

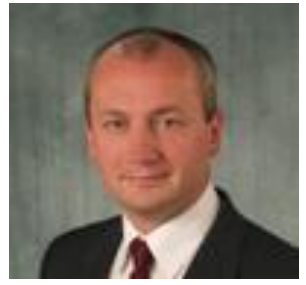

Andreas Lischke, DLR Berlin. ANDREAS.LISCHKE@, DLR.DE

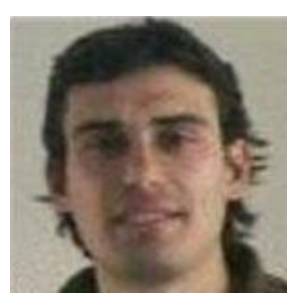

$$
\begin{aligned}
& \text { Alex Freixas } \\
& \text { IDIADA Automotive } \\
& \text { Technologies S:A } \\
& \text { AFREIXAS@ } \\
& \hline \text { IDIADA.COM }
\end{aligned}
$$
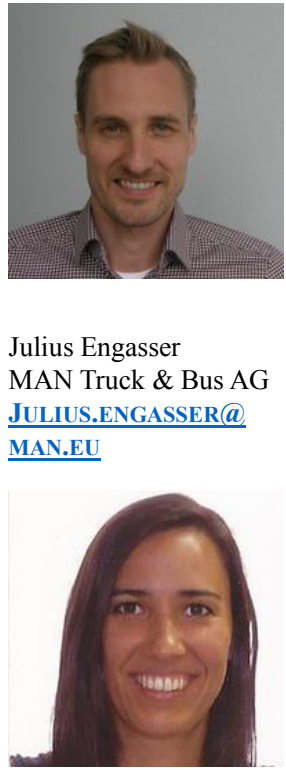

Marta Tobar IDIADA Automotive Technologies S.A MARTA-TOBAR@ IDIADA.COM

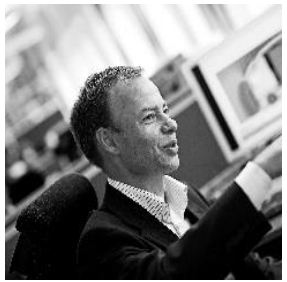

Dr. Per Elofsson Scania PER.ELOFSSON@ SCANIA.COM

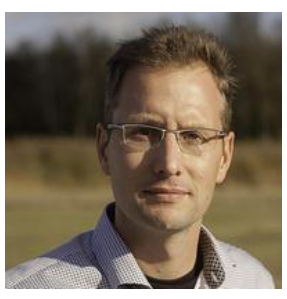

Gertjan Koornneef

TNO

GERTJAN.KOORNNEEF @.TNO.NL

\section{Introduction}

The transport sector contributes to about $25 \%$ of total $\mathrm{CO} 2$ emissions in the EU and is the only sector where the trend is still increasing. Taking into account the growing demand on the road transport system and the ambitious targets of the EC's Transport White Paper ${ }^{1}$, it is paramount to increase the efficiency of freight transport.

The vision of the AEROFLEX project is to support vehicle manufacturers and the logistics industry to achieve the coming challenges for road transport.

The objective of the AEROFLEX project is to develop and demonstrate new technologies, concepts and architectures for complete vehicles with optimised aerodynamics, powertrains and safety systems as well as flexible and adaptable loading units with advanced interconnectedness contributing to the vision of a "physical internet"2 The optimal matching of novel vehicle concepts and infrastructures is highly important, requiring the implementation of smart infrastructure access policies for new truck concepts, load carriers and road infrastructure. 


\section{Objectives}

\subsection{Goal and technical objectives}

The specific technical objectives, main innovations and targeted key results are:

1. Characterise the European freight transport market for 2035 (map, quantify and predict), the drivers, the constraints, the trends, and the mode and vehicle choice criteria

2. Develop new concepts and technologies for trucks with reduced drag, which are safer, comfortable, configurable and cost effective and ensure satisfaction of multimodal customer needs under varying transport tasks and conditions.

3. Demonstrate potential truck aerodynamics and energy management improvements with associated impact assessments of the new vehicle concepts, technologies and features.

4. Drafting of coherent recommendations for revising standards and legislative frameworks in order to allow the new aerodynamic and flexible vehicle concepts on the road.

5. Achieve an overall 18-33\% efficiency improvement in road transport / long haulage by 2025+.

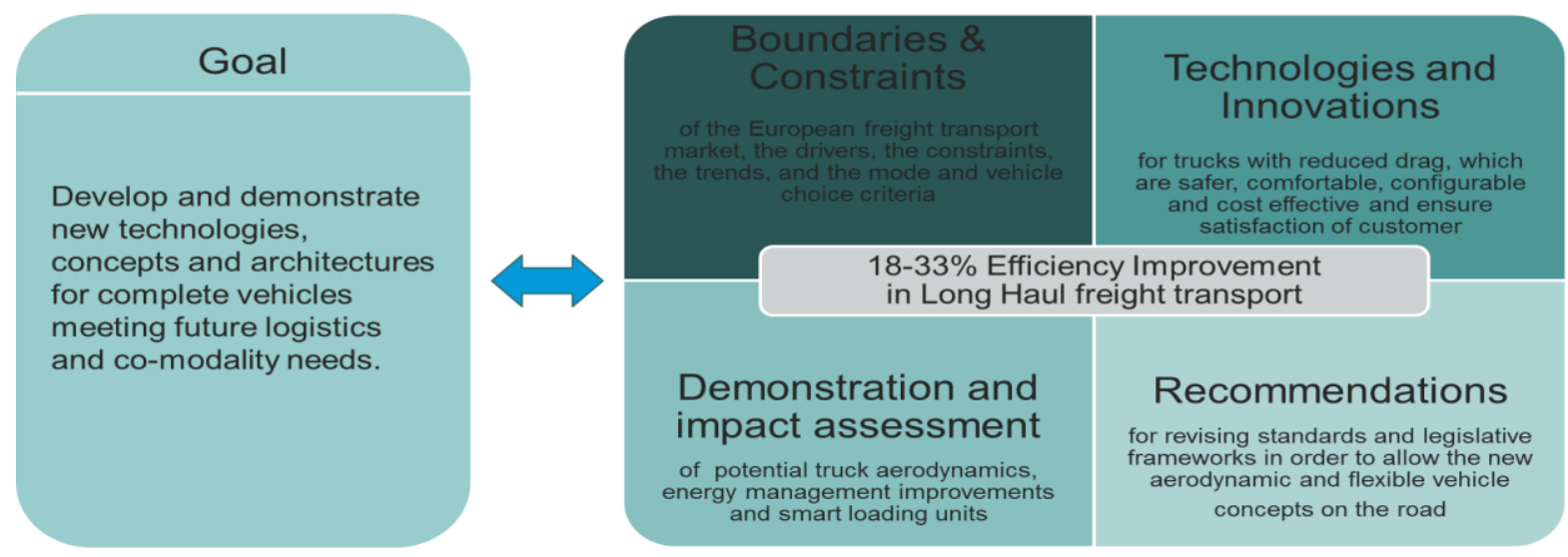

\section{Figure 1 - Goal and key objectives of AEROFLEX}

\subsection{Baseline}

The technical baseline for the AEROFLEX project includes recent and ongoing EC-funded research projects, such as CONVENIENT, ECOCHAMPS, TRANSFORMERS and FALCON.

The regulatory baselines are current and upcoming EC directives. The EC96/53 directive addresses the standard vehicle portfolio of $16,5 \mathrm{~m}, 18,75 \mathrm{~m}, 25,25 \mathrm{~m}$ up to $40 \mathrm{t}$ and $44 \mathrm{t} \mathrm{GCW}$ (Gross Combination Weight) in combined transport. The upcoming amendment EC2015/719 will relax the requirements on the dimensions to accommodate new aerodynamic and safety devices. The directive EC582/2011 defines the allowable emissions and the current EURO 6 standard.

\subsection{Sounding Board}

The project is seen as key for the European road transport and logistics and has the full support from ACEA, EUCAR, ALICE and IRU. This support is mobilised through the Sounding Board that includes key representatives from all stakeholders: Industry, logistics, authorities, policymakers and NGOs. Currently already 45 members have applied sharing and working within the project. 


\section{Research approach}

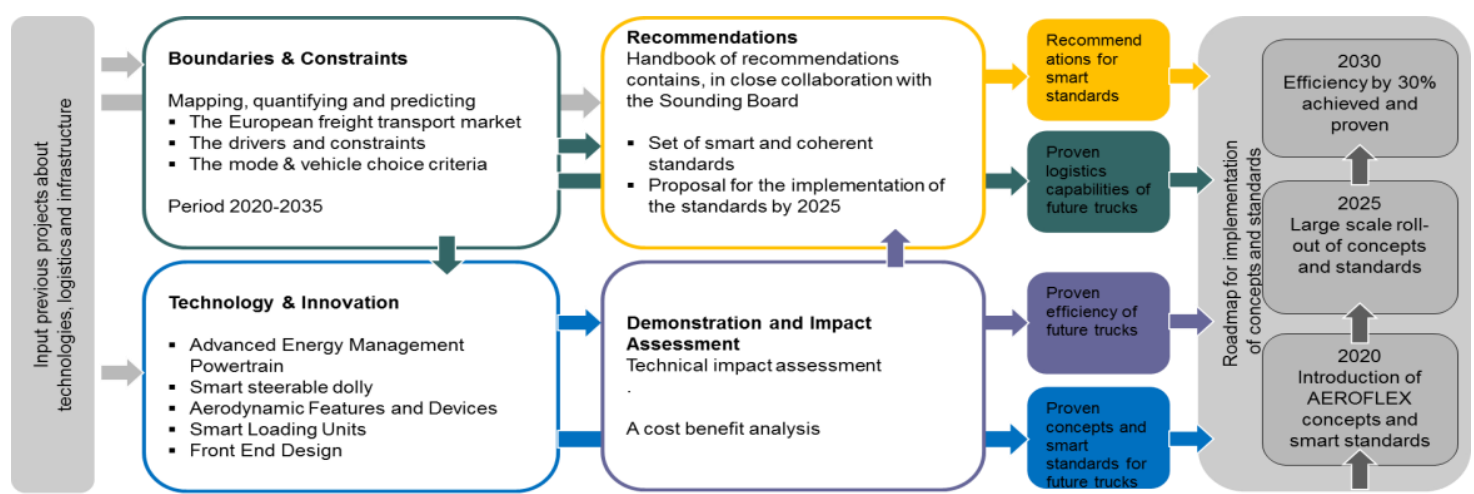

Figure 2 - Concept and Approach of AEROFLEX

\subsection{Concept and Approach}

At the left (in Figure 2), the input from other projects with respect to technologies, logistics and infrastructure is represented as being the starting point for the AEROFLEX project.

On the top left, the green-colored "Boundaries and Constraints" block represents the activities of mapping, quantifying and predicting of the European freight transport market, the drivers, the constraints, the trends and the mode and vehicle choice criteria in the period $2018-$ 2035. This information is captured in a comprehensive set of freight transport data and trends that will be used in scenario assessments to determine the potential of new vehicle concepts and loading units in terms of managing transport flows, modal shift capabilities and environmental impact (GHG emissions).

On the bottom left, the blue-colored "Technologies \& Innovations" block indicates the selected truck technologies and concepts: The key innovations are:

- An Advanced Energy Management Powertrain (AEMPT) architecture and control for distributed electric hybrid powertrains with an optimised energy management system and standardized interfaces for multi-brand compatibility and optimal interchangeability;

- A smart steerable dolly with energy storage for EMS vehicles and enabling 'autonomous' maneuvering at hubs and docking stations;
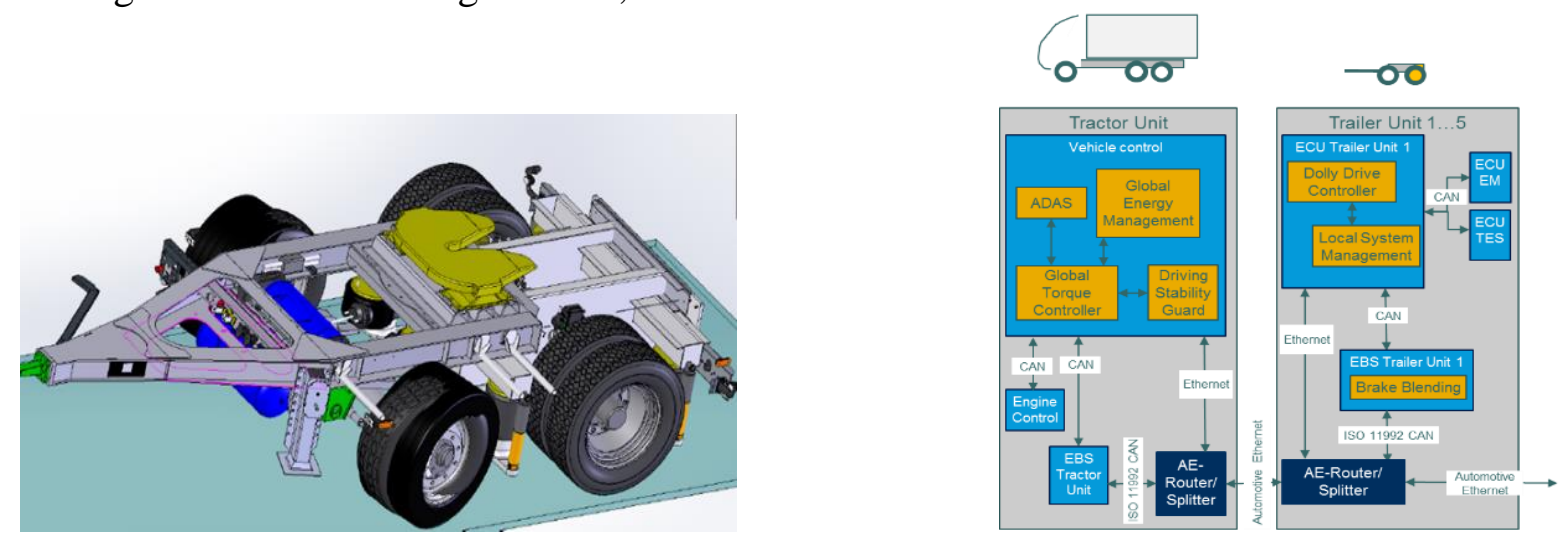

Figure 3 - Concept of AEMPT and Smart steerable dolly 
- A set of Aerodynamic Features and Devices for the Complete Vehicle to reduce drag that are adaptable to their logistics task and circumstances:

o Active geometry: active air deflectors, active side skirts, inflatable gap sealing, extending air deflectors, adjustable 5th wheel, retractable trailer, adaptive rims, adjustable underbody fairings, changing the ride height, adaptable trailer shape, movable boat-tail and rotating cylinders;

o Passive geometry: covered underbody, rear wheels, boat-tail and trailer chassis covering; o Active flow control: tangential blowing, suction, plasma actuators, synthetic jets and base bleeding;

o Passive flow control: vortex generators, air curtains and porous surfaces;

- Smart Loading Units for overall efficiency gains by separate platforms for volume and weight freight and by more effective loading space utilisation;

- An Innovative Front End Design for improved aerodynamics and to help ensure survivability of vulnerable road users in crashes up to $50 \mathrm{~km} / \mathrm{h}$.

On the bottom right, the purple-colored "Demonstration and Impact Assessment" block regards the evaluation of the 2 vehicle demonstrators which will be conducted together with the technical impact assessment of the new vehicle concepts, technologies and features developed. This includes a coherent test matrix of the operational performance, safety aspects, fuel consumption and pollutant emissions of the demonstrator vehicles for specific use cases on test track and in on-road tests, and in wind tunnel tests on scale models. A cost benefit analysis on vehicle concept level and underlying technologies and systems will also be performed. The targeted end TRL level is 7 to 8 .

On the top right, the orange-coloured "Recommendations" block regards the process of drafting recommendations for a set of smart and coherent performance based standards for future trucks, load carriers and road infrastructure, including a proposal for the implementation of the performance based standards by 2025 for policy makers and regulatory bodies. This so-called Handbook of Recommendations will be finalised based on extensive consultations with the stakeholders and Sounding Board.

\subsection{Context and challenges}

A paradigm shift in logistics and truck design is needed to make future transport sustainable, more efficient and safer. Today's transport is responsible for almost $25 \%$ of the GHG-emissions in the EU, and the demand for transport will increase. The ITF Transport Outlook 2015 expects four times as much international freight trade by 2035 , serving a population of which $\sim 70 \%$ lives in cities and which will change its consumption behaviour to "using instead of possessing". At the same time, the Paris Agreement (aimed at reducing emissions and limit global warming) requires Europe to emit $80-95 \%$ less GHGs. As road transport is responsible for $>90 \%$ of transport emissions in 2013, these conflicting trends present the European transport industry with an immense challenge. 

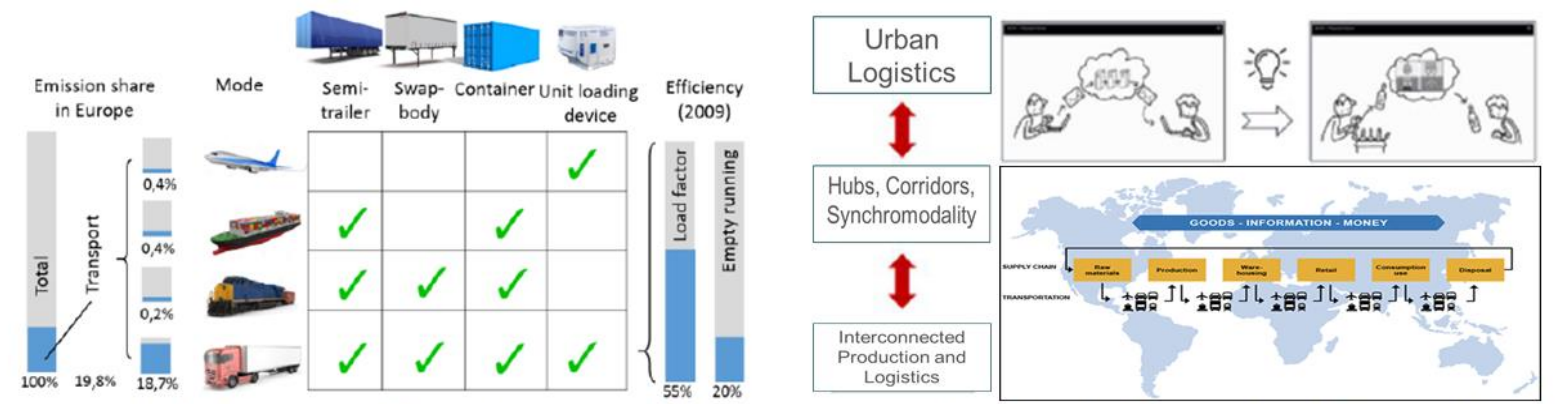

Left: Transport modes, loading units and share in emissions of the $20 \%$ of GHG emissions in Europe related to transport. ${ }^{9,10}$ and transport efficiency of road transport in Europe. ${ }^{11}$ Right: Physical Internet concept.

\section{Figure 4 - European challenges to meet Paris Agreement}

The significant room for improvement relates to the fact that trucks can be made more fuel efficient. Trailers are often not fully loaded. Until now, efficiency improvements have been largely achieved by standardizing loading units (i.e. trailers, swap-bodies, containers and unit load devices) and packaging units (i.e. Euro pallets, bulk boxes, etc.). Today goods and freight are shipped in standard-sized loading units. These units could easily be shipped by different means, i.e. intermodal transport for faster loading and unloading. Furthermore in 2016 the average load factor was less than $60 \%$, with empty trucks representing $20 \%$ of transport mileage. The presence shows that the daily transport capacity is severely under-used. Trucks today still emit $20 \%$ above the 2030 target. On top of that, there were 3,850 casualties and 13,000 serious injured due to truck incidents Europe-wide in $2014^{3}$.

Today, the existing standards do not allow for significant efficiency improvement or major optimisation. Loading units are not fully interchangeable. In addition, due to the highly limited use of available information, loading units are not used as efficiently as possible. By that the existing transport system cannot meet the dynamic demands of future long- distance, inter-urban and urban transport. Concepts must be developed to enable the full transport matrix in order to use the infrastructure optimally.

Integration of production and logistics will enable a higher degree of efficiency. The vision is to arrive at the physical internet; integration of production, logistics and transport; open systems to support the integration; logistics and freight in a Multimodal system, enabling the optimal use of the infrastructure through corridors, hubs \& spokes. The loading unit is the central element carrying the load, able to be transported by any mode. For road transport dedicated vehicles, being adaptable and flexible carrying mode compatible loading units, to suit efficient long distance, inter-urban and urban transport. Wireless digital tagging allows high-performance logistics centres to trace goods and modules, and direct them through modes and routes. 

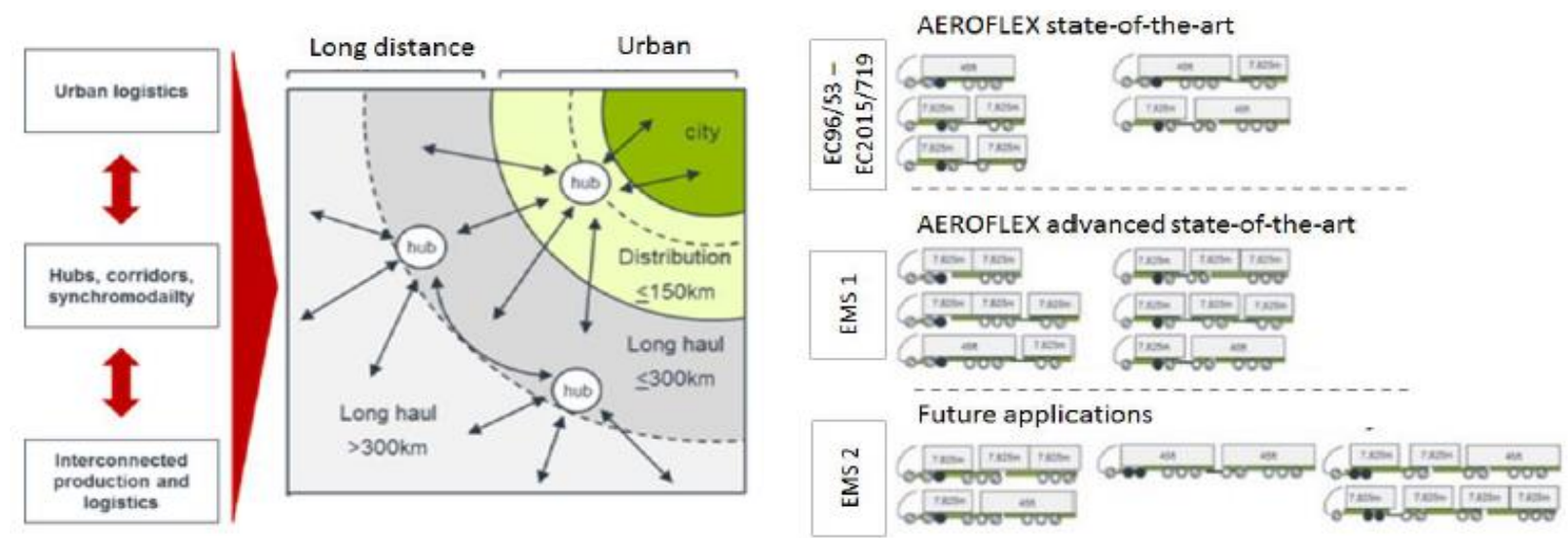

Figure 5 - Framework to clean and efficient transport as contribution to the Paris Agreement

Industry and policymakers are preparing European standards for improved multimodality. The current EC96/53 ${ }^{12}$ directive and the upcoming amendment EC2015/719 in which masses and dimensions of the complete vehicle will be re-defined.

Within the ACEA a task force has defined a vehicle portfolio, seen as relevant for transportation of freight along European corridors and in the regions based on the use of mode compatible loading units. The vehicle portfolio is build up in different groups based on the current mode compatible loading units with a maximum length of $45 \mathrm{ft}$ for a semi-trailer and a $7.825 \mathrm{~m}$ swap body for a truck / trailer combination (Figure 5).

The FALCON project is working on a set of Smart Infrastructure Access Policies, performance based standards (PBS) for the safe and efficient use of the vehicle portfolio and access standards for the safe and efficient use of the infrastructure.

Within the OECD/ITF a task force is focusing on measures to improve transport efficiency by either new vehicle concepts a/o guidelines how to bring these vehicle concepts on the road.

\section{Results}

\subsection{Expected results}

The Green Vehicles H2020 call "Aerodynamic and flexible trucks" (GV-09-2017) requires a contribution to "climate action and sustainable development by an overall efficiency gains of at least $18-33 \%$, demonstrated on real platforms".

In this context, the AEROFLEX project will develop the knowledge, concepts and technology to improve the efficiency of long-range freight vehicles by $18-33 \%$ while drawing up recommendations for implementing the results within European regulations and in the transport and logistic industry.

This overall efficiency target will be achieved by broken down targets shown below in Figure 6: 


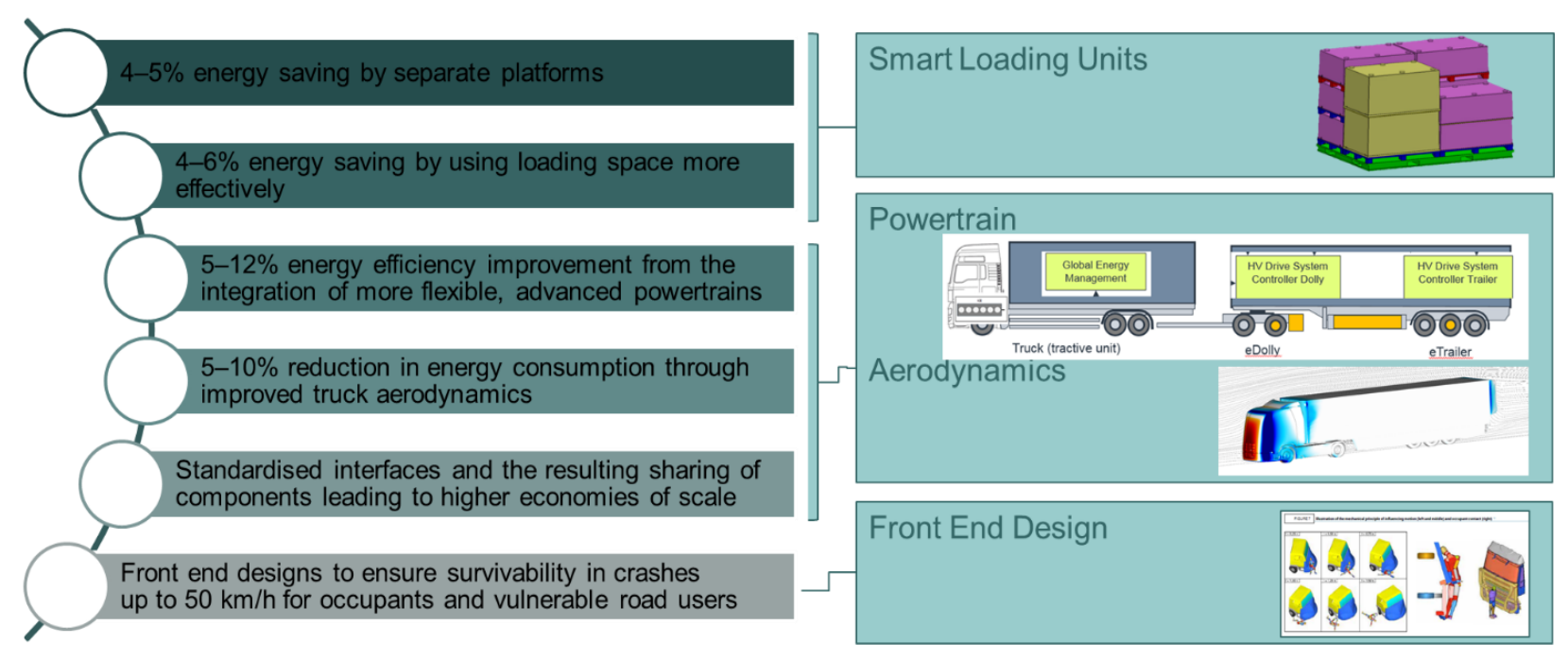

Figure 6 - Key targets broken down in field of actions

\subsection{Milestones}

Milestones are defined as control points in the project, to report the progress, to discuss and agree on the results achieved at that stage and to discuss and agree on the next steps.

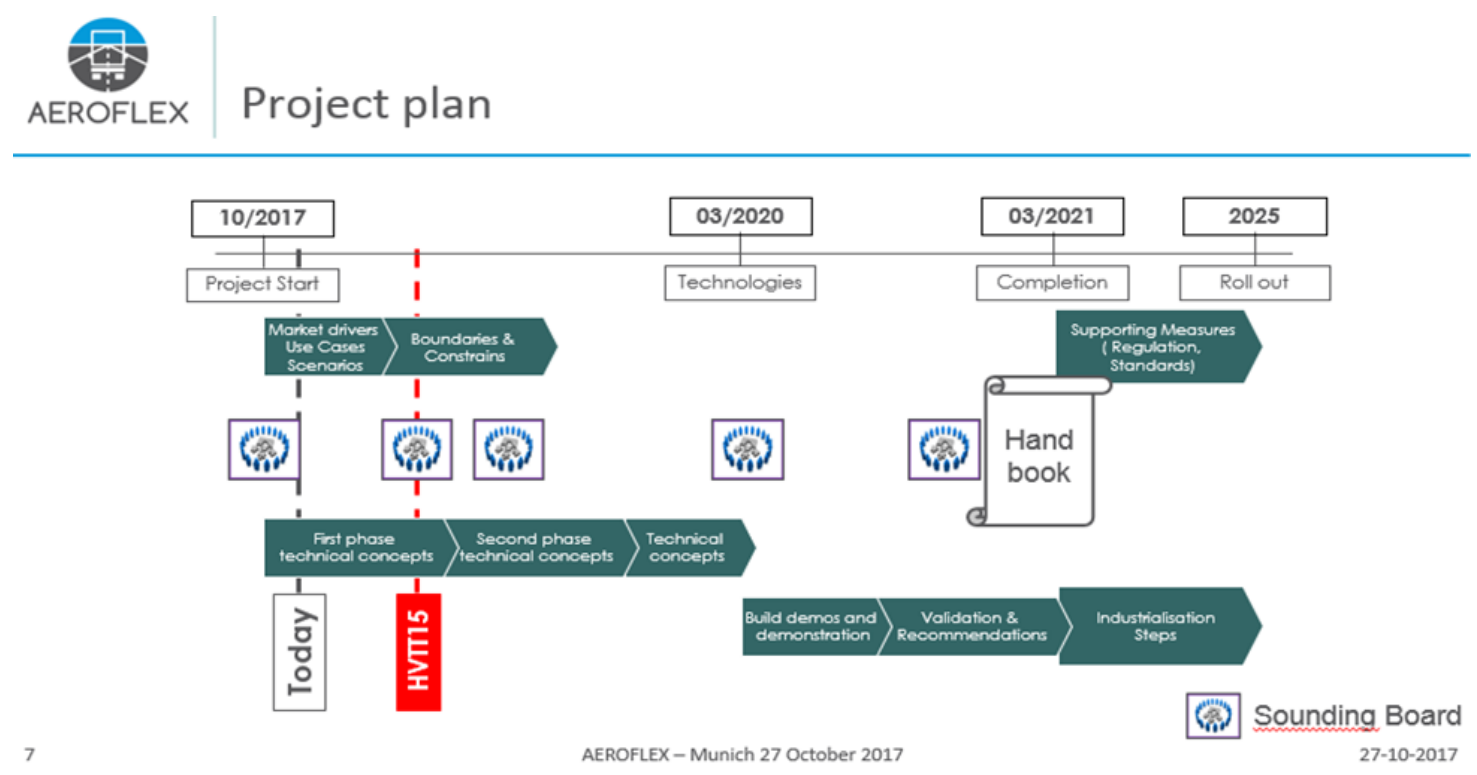

\section{Figure 7 - Project plan}

The project plan shows the most important milestones. In total 9 milestones are defined, the green arrows represent the content of each milestones. The last two will be incorporated in the Handbook. At each stage the sounding board is invited to discuss the achieved results so far and agree on the next steps.

The first phase of the project will be closed in October 2018.

Market drivers, use cases, scenarios and first technical concepts. 


\subsection{First results out of the first project phase}

\subsubsection{Market drivers and use cases (Deliverable 1.1)}

The deliverable 1.1 contributes to the overall project objective by describing the needs of the European logistics market in order to enable a vehicle development in line with the market requirements. The objectives of this deliverable are:

- to describe the European transport market

- to describe trends and market drivers in logistics

- to describe variables which influences actor's modal choice in freight transport

- to derive first recommendations regarding use cases coming from the market analysis.

The results of the deliverable 1.1 are used in other work packages to support the selection of use cases. A first stakeholder workshop has shown that it is difficult to translate the requirements of the logistics service providers directly into technical details of new vehicle concepts.

Therefore it wasn't possible to define primary candidates immediately and solely based on the input that was given by the FALCON project.

Instead, the results are based on the one hand on the analysis of literature and reports of European projects like TRANSFORMERS, FALCON or ALICE. On the other hand a first workshop with stakeholders (e.g. logistics service providers, shippers) have been conducted and analysed regarding user needs and requirements. The results and requirements are compiled as follows.

\section{Increase of efficiency for freight transport}

First of all, the improvement of efficiency is one important driver of European freight transport market. Co-modality and synchromodality are key elements to improve the efficiency. Freight transport should be organized by the consideration of the strength and weaknesses of the transport modes that are relevant to fulfil the requirements of the shipper that are defined by lead and transport time, weight and volume of the order /the shipment and further specific costumer and good related characteristics. The transport by only one transport mode could be the most efficient way in case the strength of this mode fulfil the given constraints, e.g. to carry goods due to time constraints, direct link between origin and destination without detours, availability of infrastructure and specialised equipment, sum of working time. Furthermore, it is necessary to fulfil the customer related expectations regarding transport costs.

The available European data shows that in terms of tonne-kilometre, about $80 \%$ of all freight transport is realised on long haul. Freight transport services up to $150 \mathrm{~km}$ are also relevant for new vehicle concepts in combination with smart loading units in order to support more efficient transport services at the interface between long and short distance transports e.g. in terminals and hubs. From the perspective of tonne-kilometre, new vehicle concepts could address all goods classes and not only selected ones due to the objective to develop a configurable and costefficient vehicle concept that is not dedicated for only some commodities. 

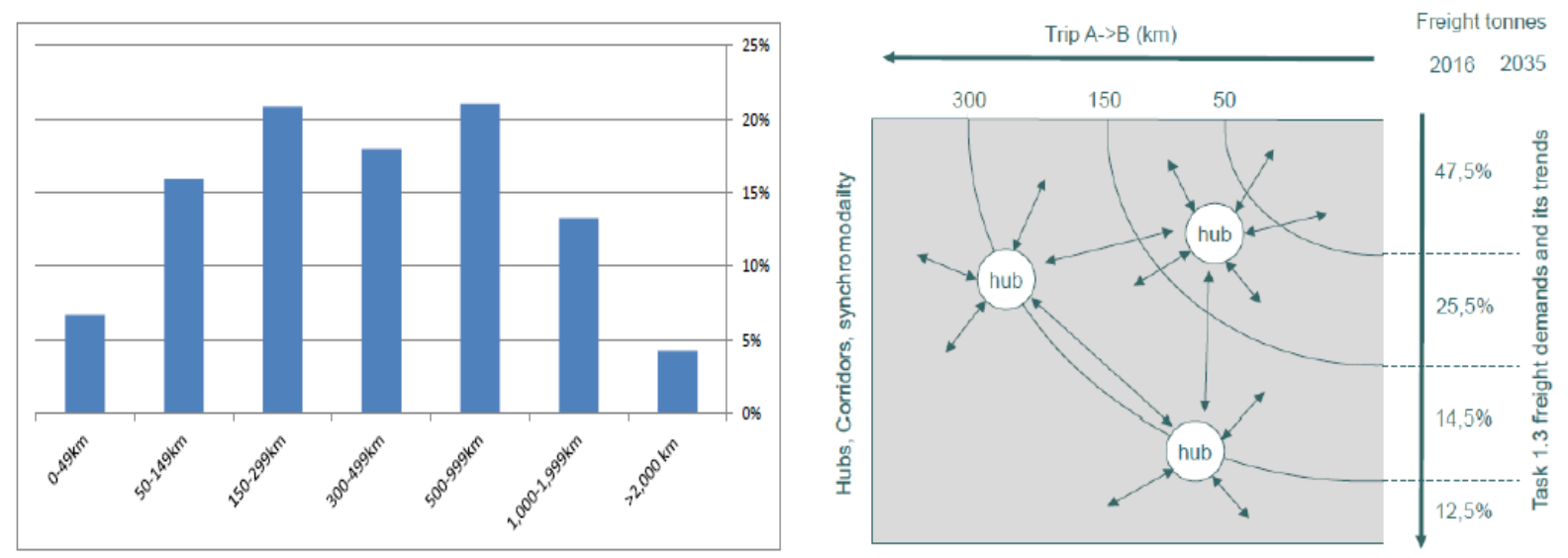

Figure 8 - Distribution in tonne-kilometre of European transport market related to the transport distance of the freight (EUROSTAT 2018c). Transport demand related to transport distances (EUROSTAT 2018c)

\section{Vehicle concepts should be developed for low density goods, long transport distances and high revenue logistics segments}

New vehicle concepts should address good classes with high transport performance measured in tonne-kilometre (e.g. food products, beverages and tobacco, agricultural products) in combination with long transport distances. Furthermore, the potential revenues in logistics segments (e.g. Contract Logistics, full and less than truck load with palletized goods and Courier/Express/Parcel) should be considered. These segments should be addressed, because the balance between market size, expected revenues and small order sizes expect a high demand for advanced vehicle concepts using modular loading units. Finally, it is recommended to realize an optimum trade-off between payloads and transport volumes in order to maximize the use of the loading capacities.

\section{Fast and frequent road transport between hubs and industrial sites become important}

Due to the increasing amount of courier/parcel/express cargo and general cargo, hub and spoke concepts are increasingly used to consolidate the shipments and thus, to increase transport efficiency. Therefore, a promising and growing segment for new truck concepts can be identified in transports between hubs (e.g. terminals, ports, huge warehouses) as well as between industrial sites and hubs. Here, it is essential that loading units can be optimally manoeuvred and placed at the gateways in cross-docking stations or in warehouses, even if there are limited infrastructure conditions. Further, the organisation of a fast exchange of loading units between different vehicles or between transport modes is important.

\section{New vehicle concepts have to be compatible with the existing infrastructure}

Infrastructure conditions and constraints of the existing road infrastructure - road, bridges, yards, driveways, roundabouts, parking areas and docks - are key issues for new vehicle concepts.

Currently, most parking areas and docks are not suitable for long commercial vehicles. The new vehicle concepts should be compatible with the existing road infrastructure to avoid an extensive 
enhancement of the European road infrastructure or sophisticated technical solutions supporting manoeuvring in confined spaces on motorways and inter-urban roads.

\section{Platooning, autonomous driving and the digitalization of logistics processes are relevant trends}

The digitalization of logistics processes supporting the driver, simplifying vehicle routing and route planning, and enabling the monitoring (e.g. smart loading units) of the whole transport chain is ongoing. Based on these digital opportunities, new transport services and processes are expected to emerge. Further approaches (in particular platooning and automated driving) reduce the stress for the driver and may contribute to a reduction of transport costs. However, they require sensors, communication technology and energy supply within the vehicle.

\section{Further trends with an effect on the transport and the vehicle are seen in:}

- Dematerialisation, i.e. the amount of materials used in products might be reduced.

- 3D-printing technology will be developed, i.e. personalised, small scale local production in regional production sizes or for spare parts retailing.

- Postponement of final product assembly, i.e. local assembly close to the consumer, leading to the transport of intermediate products (parts and components) rather than final products, with the potential to reduce the amount of space required for transport.

- Transport of Intermediary goods instead of final products is increasing and may enable a higher packaging efficiency and higher density of goods in the loading unit. This may help to meet volume restrictions.

\section{Use Cases should represent the European transport market}

The AEROFLEX project develops innovative vehicle concepts for a major percentage of the European transport market, which shall simultaneously contribute to an efficient overall freight transport system. The use cases considered in the AEROFLEX should meet the requirements of significant sub-markets in the current transport market in Europe. Based on the analyses we conducted, the uses cases should:

- include own account transports as well as transports conducted by own company and conducted by third parties (e.g. by logistics service providers)

- offer the possibility to use intermodal transport chains in cases of long transport distances

- address preferably logistics segments with high expected demand for advanced vehicle concepts like Contract Logistics, full and less than truck load with palletized goods and Courier/Express/Parcel, food products, beverages and tobacco

- address transports that are mainly conducted on motorway and inter-urban roads today. 
Use case: Country A - Country B roundtrip

The use case describes a typical roundtrip delivery from country A to country B:

- Milk run collection and delivery on outward journey

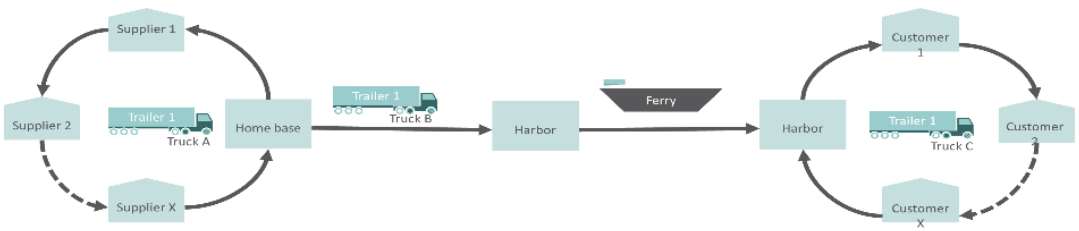

- Full truckload collection and delivery on return journey

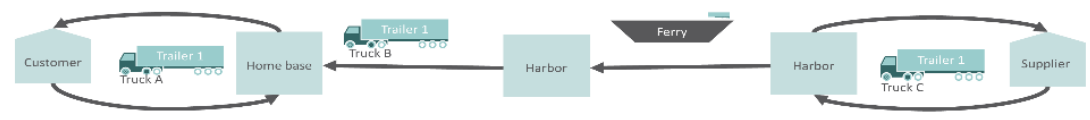

\section{Figure 9 - Example of a use case}

It is not sufficient to identify and validate primary candidates only based on literature analyses and aggregated European transport and logistics data. Instead, is additionally necessary to get more information in direct contact with stakeholders and potential users of new vehicle concepts. Thus, further stakeholder workshops will be conducted within the Work Package 1. The results will be described in the deliverable 1.2, September 2018.

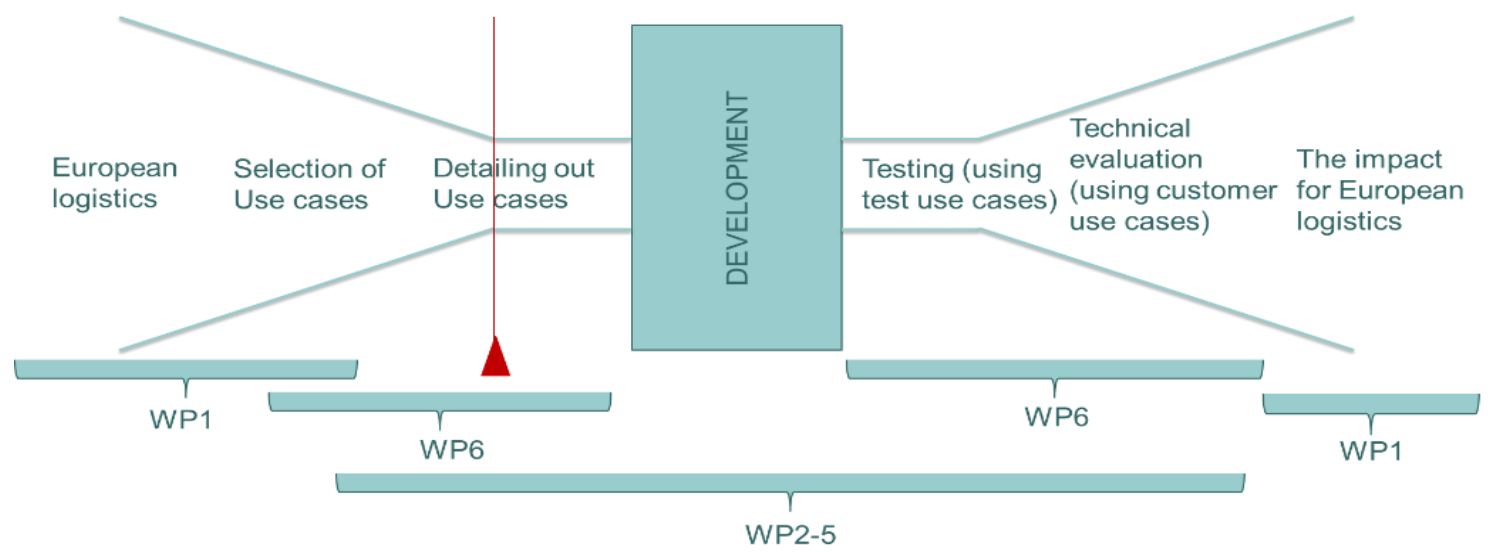

Figure 10 - Role of Use cases for the evaluation of new vehicle concepts

\subsubsection{Smart Loading Units (Deliverable 4.1)}

The aims is to develop and design solutions for prioritized transport segments where transport flows are considerable and where the impact of efficiency improvements is high. Flexible solutions for load optimization and load efficiency of the relevant European vehicle portfolio (vehicle combinations e.g. single trucks, tractor and semitrailer combinations $(16.5 \mathrm{~m})$, and truck, dolly and semitrailer combinations $(25.25 \mathrm{~m})$ ) have to be developed to improve transport efficiency of freight and logistics in a multi-modal context. 
In order to achieve the various goals the involved partners based their research methodology on three aspects: (1) a literature analysis of all relevant studies, projects, articles, (2) organisation of specific workshops and conduction of bi-lateral interviews with relevant stakeholders and (3) collection of requirements from other AEROFLEX WPs. For the purpose of this project, the concept of 'Smart Loading Units' (SMLs) should at least cover the following features and functions: intelligent and safe, full access security, load optimisation, fast interoperability, aerodynamic design, telematics-riendly and fit for intermodal.
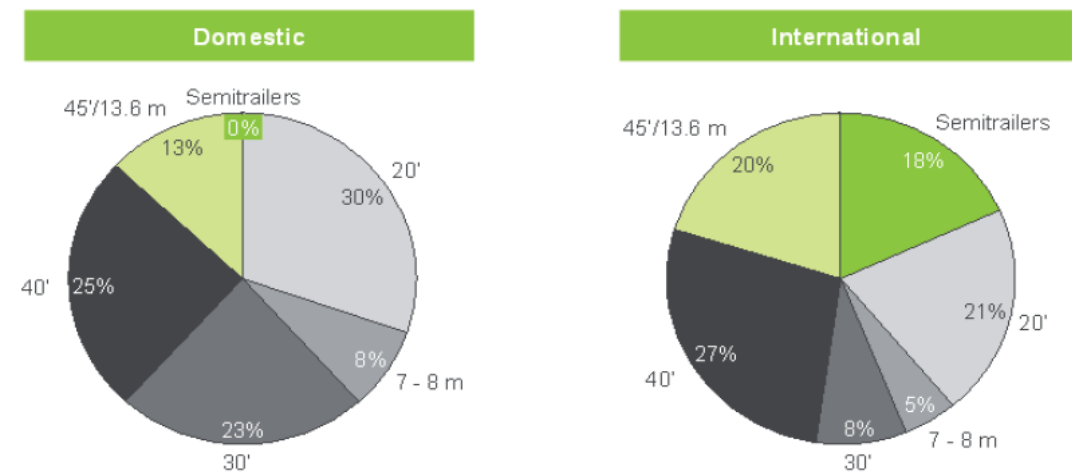

Figure 11 - Loading units in domestic and international Combined Transport in 2015 source: BSL Transportation Consultants GmbH \& Co. KG. 2017

The analysis of the various Combined Transport markets, in particular the road-rail combination demonstrates clearly that the most utilised loading units is the standardised maritime container (20', 30' and 45'), both in international and domestic CT (maritime hinterland transport). However, the continental CT market with swap bodies and semi-trailers is in progress with a clear trend of shifting more semi-trailers onto rail. It is agreed that within the AEROFLEX project the new smart loading unit should be compatible with rail wagons and ferries and should be designed and compatible for vertical craning. Among the 1,000 available terminals in Europe, the main used transshipment technologies in combined transport terminals are still cranes and reach steacker necessary for the vertical transshipment. However, it has been recommended that the SML should be tested and demonstrated for both types of handlings (vertical and horizontal).

The digitalisation of the transport freight market is in progress thanks to namely the transformation of the assets (semi-trailers, boxes, wagons, cranes, locomotives) into smart devices necessary to fulfill the requirements of the Physical Internet concept and vision as developed by the LSPs in the ALICE platform. The end-users will benefit from these digitalised assets of a bundle of information (tracking and tracing, energy consumption, mileage...) allowing a fully (automatic) optimisation of the logistic routings taken into account the energy consumption and environmental footprint. 

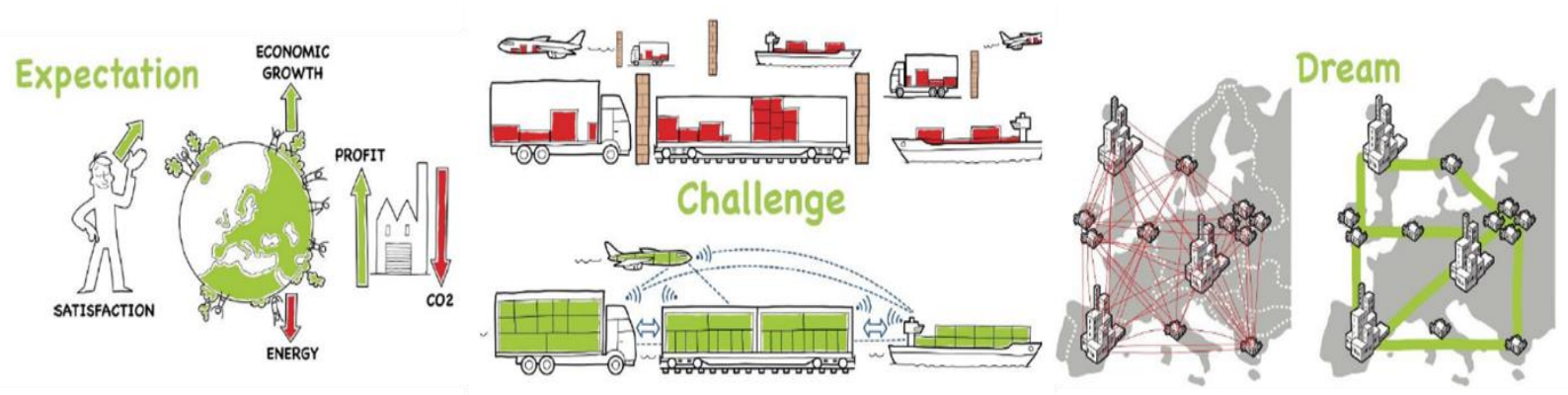

Figure 12 - digitalised assets of a bundle of information allowing a fully optimisation of the logistic routings taken into account the energy consumption and environmental footprint source: The SETRIS project has received funding from the European Union's Horizon 2020 research and innovation programme under grant agreement No 653739

Use cases relevant for the AEROFLEX project have been identified and discussed with the stakeholders. These cases are based on four criteria that can be mixed (1) a volume -based scenario (2) a weight-based option, (3) an intermodal case and (4) a distance-based case (urban, medium and long-haul transport). The pre-selected use cases (10 in total) have been briefly described at this stage. The aim is to select at least three use case with one covering intermodal transport. For all use cases, specific preliminary KPI's have been chosen and registered in six specific categories: transport efficiency, operational parameters, vehicle uptime, loading parameters, safety and limitations and digital and IoT. The final list of KPIs will be elaborated based on the input of the markets (sounding board) and of the other WPs.

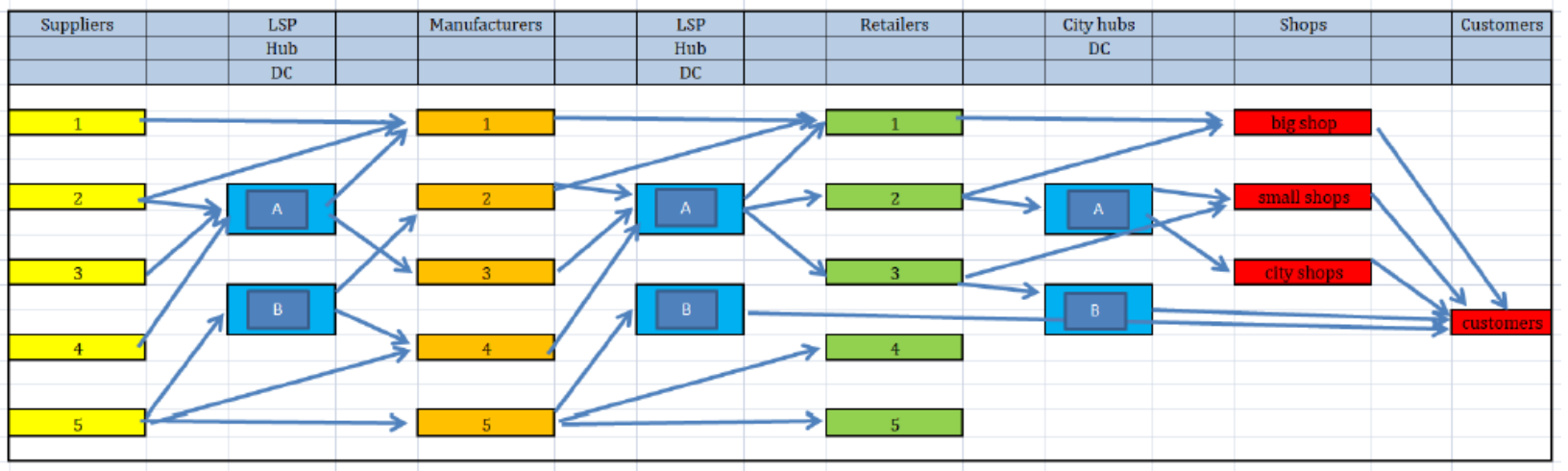

Table 1 - Overview of the complete logistic supply chain with multiple possible use cases in it. Every blue arrow representing a possible use case

Thanks to the bilateral contacts and organization of workshops with LSPs and other stakeholders of the transport chain, a first catalogue of user requirements has been established and split into categories (logistic operational aspects, operational time, flexibility, (smart) loading units). All these requirements must be taken into consideration when choosing the use cases of the AEROFLEX project. 


\subsubsection{Aerodynamic concepts for the complete vehicle (Deliverable 3.1)}

Different concepts are analysed, with the aim of reducing the aerodynamic drag for heavy trucks, and provides initial estimates of the drag reduction potential of the concepts. Based on the work performed in the Task 3.1 , both a set of concepts that should be investigated further within the Work Package and a set of concepts for which no further work will be performed within the project have been identified. Recommendations for further work on the selected concepts, and motivations for not promoting some concepts are also described in the report.

\begin{tabular}{|c|c|c|}
\hline & Geometry & Flow control \\
\hline Active & $\begin{array}{l}\text { 1. Active side skirt extension } \\
\text { 2. Retractable trailer } \\
\text { 3. Changing the ride height } \\
\text { 4. Adaptable trailer shape } \\
\text { 5. Moveable boat-tail }\end{array}$ & $\begin{array}{l}\text { 1. Tangential blowing } \\
\text { 2. Boundary layer suction } \\
\text { 3. Plasma actuators } \\
\text { 4. Synthetic jets } \\
\text { 5. Base bleeding }\end{array}$ \\
\hline Passive & $\begin{array}{ll}\text { 1. } & \text { Covered underbody } \\
\text { 2. } & \text { Covered rear wheels } \\
\text { 3. } & \text { Boat-tail } \\
\text { 4. } & \text { Trailer chassis covering }\end{array}$ & 1. Vortex generators \\
\hline
\end{tabular}

\section{Figure 14 - Aerodynamic concepts after first analyses}

As a result of the work conducted in this Task, it has been decided to proceed with most of the initially defined concepts for reduced aerodynamic drag. For the concepts adjustable underbody fairing, adjustable air dam, rotating cylinders and porous surfaces, no further development will be made within the current project. The decision to stop the development work on these concepts was based on a combination of low or uncertain drag reduction potential, high complexity and redundant functionality (identical functionality achieved with a different concept).

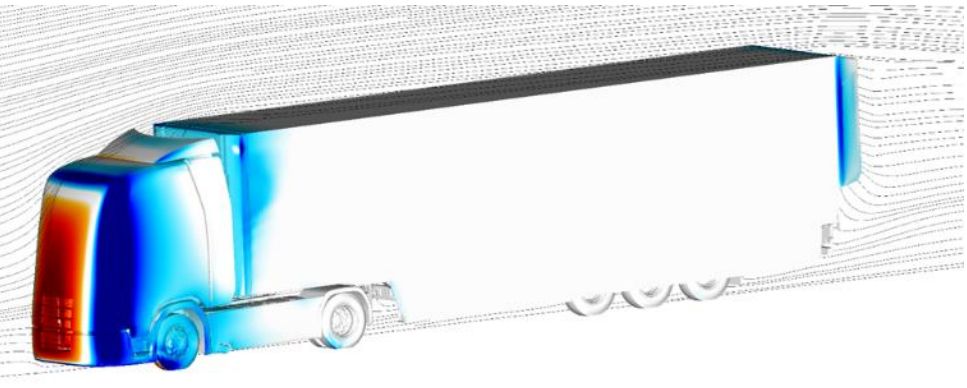

The drag reduction potential from the selected concepts have different level of confidence. Some estimates are based on detailed CFD simulations or wind tunnel tests on truck geometries, whereas others are based on published research results on other vehicles types or bluff bodies.

\section{Figure 15 - CFD model of tractor semi-trailer}

This is in line with the plan for the Work package, where detailed performance estimates will be available once the concepts have been developed further in the Tasks that follow. 
A summary of the initial performance estimates and a comparison with the targets for Work package 3 (WP3) are shown in table 1 below.

\begin{tabular}{|l|c|c|c|}
\hline Case & Estimated $\Delta C_{D} A\left[\mathrm{~m}^{2}\right]$ & Estimated $\Delta \mathrm{C}_{D} \mathrm{~A}[\%]$ & Targeted $\Delta \mathrm{C}_{D} \mathrm{~A}[\%]$ \\
\hline Tractor semi-trailer $(16.5 \mathrm{~m})$ & $1.38-2.39$ & $22-39$ & 25 \\
\hline EMS truck trailer $(25.25 \mathrm{~m})$ & $1.38-2.43$ & $17-30$ & 17 \\
\hline Demonstrator $(E M S 25.25 \mathrm{~m})$ & $1.34-2.25$ & $16-27$ & 15 \\
\hline
\end{tabular}

\section{Table 2 - Initial performance estimates}

The uncertainty of the estimates are higher at this initial phase of the AEROFLEX project, but based on the preliminary drag reduction numbers, it is expected that all KPI's for WP3 will be met during the project.

\subsubsection{Crash scenarios (Task 5.1)}

\section{Most frequent crash scenarios}

A detailed work is performed on analyses describing and evaluating fatalities and injuries arising in crashes, the most frequent crash scenarios and investigating the critical safety factors and causes of crashes. The scope of the analysis are trucks with combination weight above 16t, and the effect of combination weight on crash rates was investigated as well. Some previous R\&D projects has been evaluated in order contribute in the definition of the Key Performance Indicators (KPI) to be used for evaluating the impact of the project on road users and HGV.

Crash data from some national accident database as well as the European crash database CARE, shows that in 2015 there were more than 1 million crashes within whole Europe, out of which 24'000 resulted in fatalities. Out of those crashes, 49'000 involved a heavy goods vehicle (HGV) as one of the crash partners. Around 3'400 of those crashes resulted in fatalities, leading to 3'800 fatally injured persons. Although crashes involving HGV's account for only $4,5 \%$ of all crashes on European road, their share of fatal crashes with 14,2\% percent is much higher. The overrepresentation of HGVs in fatal crashes calls for actions. This is especially relevant for VRUs that do not have a protective shell around them like occupants of a vehicle. Furthermore, in crashes involving HGVs and VRUs, there is a high risk of fatal or severe injuries already at low speeds due to the huge weight difference and therefore higher possible energy transfer.

\begin{tabular}{|c|c|c|c|c|c|c|c|c|c|}
\hline \multicolumn{2}{|c|}{$\begin{array}{c}\text { Crash with a } \\
\text { Car } \\
(n=487)\end{array}$} & \multicolumn{2}{|c|}{$\begin{array}{c}\text { Crash with a } \\
\text { Commercial vehicle } \\
(n=250)\end{array}$} & \multicolumn{2}{|c|}{$\begin{array}{c}\text { Crash with a } \\
\text { Cyclist } \\
(n=96)\end{array}$} & \multicolumn{2}{|c|}{$\begin{array}{c}\text { Crash with a } \\
\text { Pedestrian } \\
(n=56)\end{array}$} & \multicolumn{2}{|c|}{$\begin{array}{c}\text { Crash with a } \\
\text { Powered two-wheeler } \\
(n=37)\end{array}$} \\
\hline $\begin{array}{l}\text { Truck is B } \\
\mathrm{N}=27 \\
(6 \%)\end{array}$ & $\begin{array}{r}{ }^{601} \\
\mathrm{~B} \\
\mathrm{~A}\end{array}$ & $\begin{array}{l}\text { Truck is not A or B } \\
N=39 \\
(16 \%)\end{array}$ & 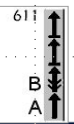 & $\begin{array}{l}\text { Truck is A } \\
N=39 \\
(41 \%)\end{array}$ & ${ }^{\mathrm{A}} \mathrm{C}_{\mathrm{B}}^{243}$ & $\begin{array}{l}\text { Truck is A } \\
\mathrm{N}=12 \\
(\mathbf{2} 1 \%)\end{array}$ & $\mathrm{A}^{421}$ & $\begin{array}{l}\text { Truck is A } \\
\mathrm{N}=5 \\
(14 \%)\end{array}$ & \\
\hline $\begin{array}{l}\text { Truck is } \mathrm{A} \text {. } \\
\mathrm{N}=17 \\
(4 \%)\end{array}$ & 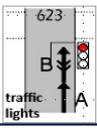 & $\begin{array}{l}\text { Truck is B } \\
\mathrm{N}=36 \\
(14 \%)\end{array}$ & 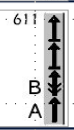 & $\begin{array}{l}\text { Truck is } A \text {. } \\
N=8 \\
(8 \%)\end{array}$ & $\left.\stackrel{R B}{\longrightarrow} T_{A}\right|^{(w)}$ & $\begin{array}{l}\text { Truck is A } \\
N=8 \\
(14 \%)\end{array}$ & ${ }_{A}{ }^{F}$ & $\begin{array}{l}\text { Truck is B } \\
\mathrm{N}=3 \\
(8 \%)\end{array}$ & 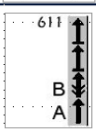 \\
\hline $\begin{array}{l}\text { Truck is not A } \\
\begin{array}{l}N=14 \\
(3 \%)\end{array}\end{array}$ & £ $\mathrm{A}$ & $\begin{array}{l}\text { Truck is A } \\
\mathrm{N}=29 \\
(12 \%)\end{array}$ & 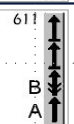 & $\begin{array}{l}\text { Truck is not A or B } \\
N=3 \\
(3 \%)\end{array}$ & 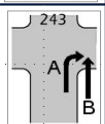 & $\begin{array}{l}\text { Truck is A } \\
\mathrm{N}=5 \\
(9 \%)\end{array}$ & ${ }^{A} \int_{\frac{E}{E}}^{241}$ & $\begin{array}{l}\text { Truck is not A } \\
\mathrm{N}=2 \ldots \\
(5 \%)\end{array}$ & $\mathrm{C}_{\mathrm{A}}^{102}$ \\
\hline
\end{tabular}

Table 3 - Frequent detailed accident types - No. Of trucks involved (Trucks above 16t, years 2000-2017) 
Most HGV crashes in Europe occur during daylight with good weather conditions und dry road surfaces. Basing on GIDAS in-depth accident database the most relevant scenarios for VRU crashes are "turning off accidents". Additionally, "Crossing/entering accident" have a high relevance for cyclists and "pedestrian crossing road" is the most common crash type for pedestrians". Crashes in longitudinal traffic" are most relevant for passenger cars and commercial vehicles as a conflict partner.

According to the scope of the AEROFLEX project, the effects of the GVW increase has been investigated. Some EU country already allows GVW above 44t. From Swedish National Crash Data heavier trucks show a significantly lower crash risk compared to today's trucks up to 44t.

\section{Conclusions and discussion}

AEROFLEX develops technologies and standards for multimodal transport in Europe and assesses the impact, to deliver cleaner, safer and more efficient road transport.

In a paradigm shift in transport philosophy, the starting point for designing logistics and trucks is the loading unit, the basic packaging element.

Technologies are developed for EC96/5312 - EC2015/719 vehicles, up to 44t GCW (Figure 1-3). An analysis will be performed for EMS1 and EMS2 vehicles up to 74t GCW for regional areas where the option for multi modal transportation is not given.

Vehicle concepts and future freight demands will be mapped, to prepare logistics service providers and carriers for multimodal transport. Activities include a scenario assessment on new vehicle concepts, including market potential and future outlook, and the definition of recommendations for a future regulatory framework.

\section{References}

[1]. Roadmap to a Single European Transport Area - Towards a competitive and resource efficient transport system (White Paper), Brussels 2011

[2]. The term "Physical Internet" was 'invented' by prof. Benoit Montreuil, who describes the Grand Challenge in logistics, i.e. how to decouple economic growth and transport demand, and who presented a roadmap for implementing the Physical Internet vision as the way to meet the grand challenge and to achieve a sustainable logistics and transport system.

[3]. Strandroth, et.al., "Head-on collisions between passenger cars and heavy goods vehicles: Injury risk functions and benefits of autonomous emergency braking”, 2012 IRCOBI

[9]. MAN T\&B Foresight \& Environment, Data 2013 European Environment Agency, 2015

[10] http://ec.europa.eu/transport/sites/transport/files/pocketbook2016.pdf

[11] Eurostat 2012 + EU Environment Agency data 2010

[12] Council Directive 96/53/EC of 25 July 1996 
HVTT15 - AEROFLEX, Tuesday October $2^{\text {nd }}$

\section{Project partners}

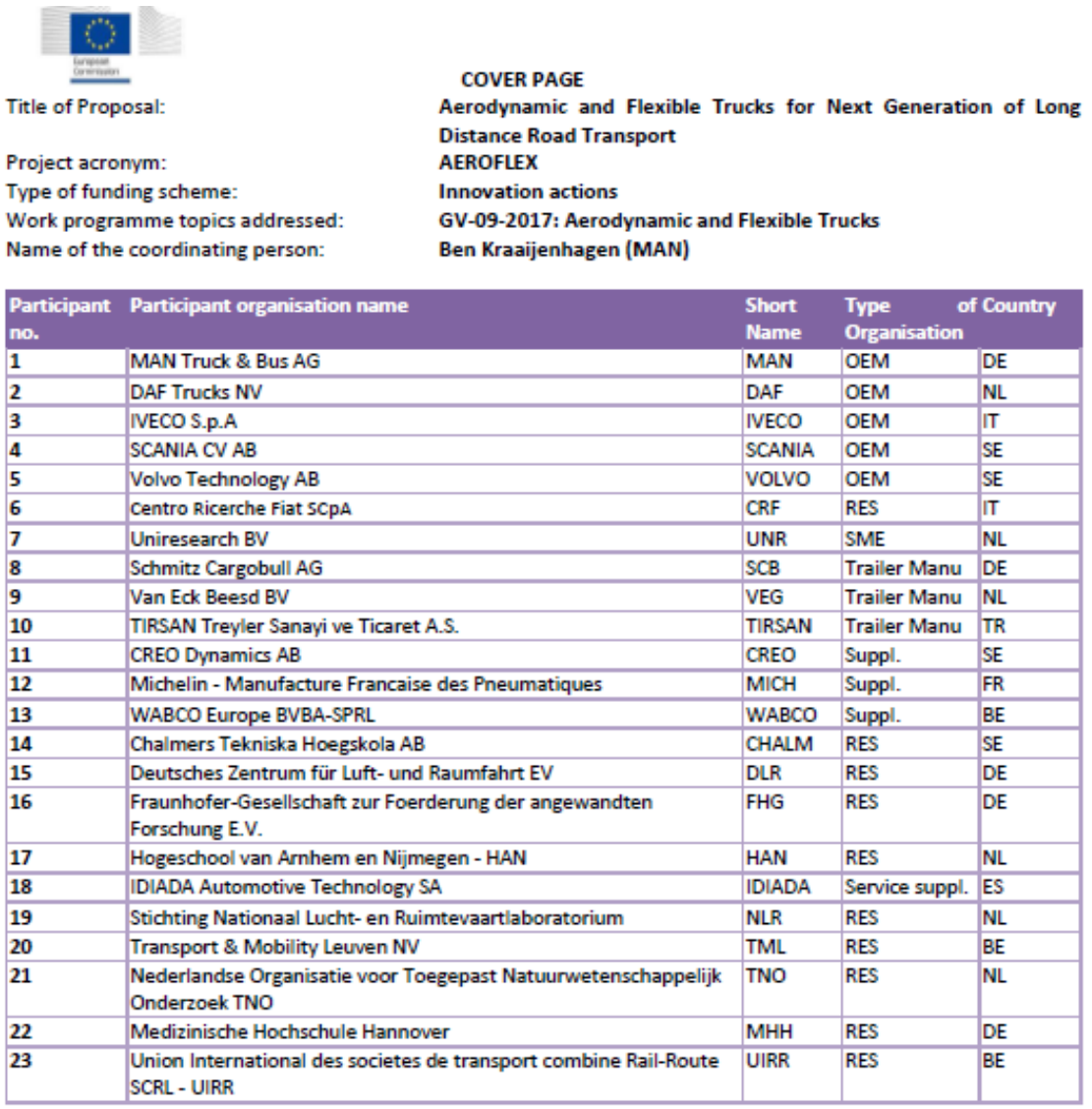

